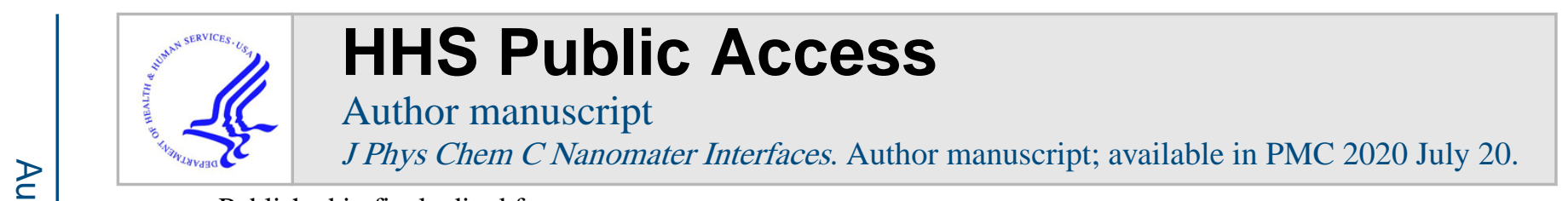

Published in final edited form as:

J Phys Chem C Nanomater Interfaces. 2019 October 3; 123(39): 24200-24208. doi:10.1021/

acs.jpcc.9b07626.

\title{
Optical Voltammetry of Polymer-Encapsulated Single-Walled Carbon Nanotubes
}

\author{
Christopher P. Horoszko ${ }^{\dagger} \ddagger$, Prakrit V. Jena ${ }^{\dagger}$, Daniel Roxbury ${ }^{\S}$, Slava V. Rotkin ${ }^{\perp}$, Daniel A. \\ Heller $^{*},+, \|$ \\ †Memorial Sloan Kettering Cancer Center, New York, New York 10065, United States \\ ¥Weill Graduate School of Medical Sciences, Cornell University, New York, New York 10065, \\ United States \\ "Weill Cornell Medicine, Cornell University, New York, New York 10065, United States \\ §Department of Chemical Engineering, University of Rhode Island, Kingston, Rhode Island \\ 02881, United States \\ ${ }^{\perp}$ Materials Research Institute and Department of Engineering Science and Mechanics, \\ Pennsylvania State University, Millennium Science Complex, University Park, Pennsylvania \\ 16802, United States
}

\begin{abstract}
The semiconducting single-walled carbon nanotube (SWCNT), noncovalently wrapped by a polymeric monolayer, is a nanoscale semiconductor-electrolyte interface under investigation for sensing, photonics, and photovoltaic applications. SWCNT complexes are routinely observed to sensitize various electrochemical/redox phenomena, even in the absence of an external field. While the photoluminescence response to gate voltage depends on the redox potential of the nanotube, analogous optical voltammetry of functionalized carbon nanotubes could be conducted in suspension without applying voltage but by varying the solution conditions as well as the chemistry of the encapsulating polymer. Steady-state photoluminescence, absorbance, and in situ measurements of $\mathrm{O}_{2} / \mathrm{H}_{2} \mathrm{O}$ reactivity show correlation with the $\mathrm{pH} / \mathrm{p} K_{\mathrm{a}}$-dependent reactivity of $\pi$ rich coatings. The nanotube emission responses suggest that the presence of photogenerated potential may explain the observed coating electrochemical reactivity. This work finds that electronic and chemical interactions of the nanotube with the encapsulating polymer may play a critical role in applications that depend on radiative recombination, such as optical sensing.
\end{abstract}

\section{Graphical Abstract}

\footnotetext{
*Corresponding Author hellerd@mskcc.org.

Author Contributions

All authors contributed to the final manuscript and approved of the final version.

Supporting Information

The Supporting Information is available free of charge on the ACS Publications website at DOI: 10.1021/acs.jpcc.9b07626.

Supporting methods, text/discussion, figures, calculations, and references (PDF)

The authors declare the following competing financial interest(s): D.A.H. is a cofounder of LipidSense, Inc., a cofounder and officer with equity interest in Goldilocks Therapeutics Inc., and a member of the scientific advisory board of Concarlo Holdings, LLC. P.V.J. is a cofounder and officer of LipidSense, Inc.
} 


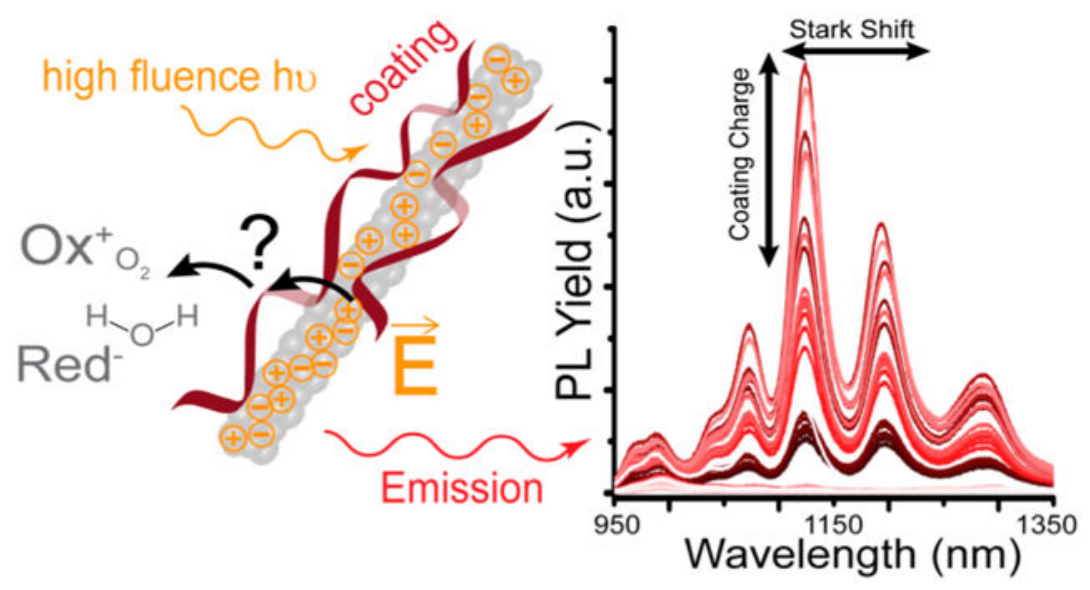

\section{INTRODUCTION}

The near-infrared (NIR) photoluminescence ${ }^{1}$ of semiconducting single-walled carbon nanotubes (SWCNTs) enables optoelectronic, ${ }^{2}$ sensor, ${ }^{3-7}$ analytical, ${ }^{8}$ and imaging applications. ${ }^{9-11}$ Upon photoexcitation, various nonlinear processes have been observed in the nanotubes, including carrier ionization, ${ }^{12,13}$ carrier multiplication, ${ }^{14,15}$ existence of trions, ${ }^{16}$ biexcitons, ${ }^{17,18}$ generation of spontaneous/long-lived charge carriers, ${ }^{19-24}$ and Auger effects. ${ }^{16,17,25-27}$ These phenomena were observed in individual nanotubes in an environment of low (nonpolar solvents, or air) or high (polar solvents) permittivity, when exposed to a range of optical fluences, with ultrafast laser sourses $22,24,28,29$ or continuous wave sources. ${ }^{30,31}$ Overall, independent of dielectric environment, photogenerated potentials near the nanotube surface were observed. ${ }^{28,31,32}$

Recent evidence shows that, for encapsulated/dispersed SWCNTs, the photoinduced excitations may interact with the coating. ${ }^{33}$ Routine preparation of colloidal suspensions of SWCNTs is achieved with a variety of coating molecules, including polymers that have $\pi$ rich electronic systems and/or electrochemically active moieties. Studies of colloidal dispersions show that semiconducting SWCNTs can sensitize, or catalyze, coating-related redox reactions. ${ }^{34-42}$ These reactions were found even in the absence of external light excitation (though not entirely isolated from ambient lighting) or voltage. ${ }^{43-47}$ The role of the coating in this activity was not defined, although the emission response of nanotubes to redox solutes was reported to be coating-dependent. ${ }^{48}$ The presence of photogenerated charge on the coating offers an explanation for observed redox sensitization. However, if the coating is not directly photoionized, the mechanisms that sensitize a reaction in suspension are not clear. Many coatings that stably suspend nanotubes, e.g., DNA and cellulose polymers, have $\mathrm{pH}$-dependent redox properties (show electrochemical response in the presence of reducing or oxidizing agents). ${ }^{49-57}$ Notably, $\mathrm{O}_{2} / \mathrm{H}_{2} \mathrm{O}$ redox activity is frequently observed in aqueous suspensions of coated nanotubes ${ }^{35,37,40,41,58-60}$ as well as in suspensions of biomolecules such as DNA oligomers in contact with dye photosensitizers. ${ }^{61}$

Herein, we investigate the excited-state electrochemical behavior of carbon nanotubes and their interaction with nonconducting polymer coatings. Two chemically distinct coatings 
were explored—single-stranded DNA (ssDNA (GT) 30 and shorter oligomers) ${ }^{45}$ and carboxymethyl-cellulose (CMC). ${ }^{46}$ We investigated the $\mathrm{pH}$-dependent response of the SWCNT emission using buffers to control the $\mathrm{O}_{2} / \mathrm{H}_{2} \mathrm{O}$ redox potential of the nanotube environment. We observed a distinct optical response of nanotubes to $\mathrm{pH}$ that mimics the nanotube response upon applied electrochemical potentials. We also found distinct photoluminescence features that corresponded to ionization constants of the SWCNT coatings. These features depend on excitation fluence, nanotube bandgap, temperature, and redox solute concentration. Coating-related photocatalysis was also observed upon exposure to relatively large $\mathrm{CW}$ laser fluences. We propose that the electrochemical character of colloidal SWCNTs can be assessed quantitatively via spectroscopy without the need for external voltage and that ionizable groups on the coatings play a distinct role in their electrochemical behavior.

\section{EXPERIMENTAL METHODS}

\section{Materials.}

CMC-SWCNTs were prepared with $5 \mathrm{mg}$ high-pressure carbon monoxide (HiPco, Unidym, Sunnyvale, CA) nanotubes mixed into $1 \mathrm{~mL} 0.1 \%$ carboxymethyl-cellulose sodium salt (Sigma C4888) in deionized water (PureLab ultra, 18.2 M $\Omega$ ). DNA-SWCNT was prepared using $10 \mathrm{mg}$ of HiPco mixed into $2 \mathrm{mg}$ of single-stranded (GT) ${ }_{30}$ DNA (IDT) predissolved in $1 \mathrm{~mL}$ of $0.1 \mathrm{M} \mathrm{NaCl}$. Both mixtures were probe tip sonicated (Sonics \& Materials, Sonics Vibracell) at $10 \mathrm{~W}$ with a $3 \mathrm{~mm}$ stepped microtip (Sonics \& Materials) in $2 \mathrm{~mL}$ Eppendorf tubes for $30 \mathrm{~min}$ in a $-20{ }^{\circ} \mathrm{C}$ cold block (Biocision) contacted by dry ice. A pulse program was used during sonication (1 min on, $15 \mathrm{~s}$ off). The resulting black suspension was bench centrifuged for $10 \mathrm{~min}$ at $30000 \mathrm{rcf}$ (Eppendorf Centrifuge 5430R); the top 90\% was ultracentrifuged for $30 \mathrm{~min}$ at $171180 \mathrm{rcf}$ (avg) (Sorvall Discovery 90SE). The top 80\% of this supernatant was removed to an Eppendorf; $500 \mu \mathrm{L}$ aliquots were exposed for 3 days to a Neodymium magnet (Applied Magnets) to clear residual metallic particulates (see Supporting Information, Figure SM1). The supernatant above the aggregate/pellet was removed and stored at $4{ }^{\circ} \mathrm{C}$. Sodium azide $(0.05 \% \mathrm{w} / \mathrm{v}$, Sigma S2002) was added to inhibit microbial growth. Working colloid was prepared using three wash-spins with deionized water in a MWCO centrifugal filter (Millipore, Amicon $100 \mathrm{kDa}, 13,000 \mathrm{rcf}, 6 \mathrm{~min}$ ) followed by a final $10 \mathrm{~min}$ table-top centrifugation ( 32 $000 \mathrm{rcf})$. Based on similar preparation procedures, $>80 \%$ of SWCNT in colloid after preparation average $136 \mathrm{~nm}$ in length. ${ }^{7}$ Other reagents and materials used in this work are reported in the Supporting Information.

Excitation fluence was measured with a power meter (Thorlabs, PM100D) and photodiode power sensor. The illumination area was calculated using the formula $d=(4 / \pi)^{*}(\lambda / D)^{*}$, where $d$ is the diameter of the focused beam, $D$ is the visual diameter of the beam on the focusing lens, and $f$ is the focal length (reported by vendor). Fluence values likely underestimate the true fluence since the true focal area is expected to be smaller than the estimated one. During all experiments, each sample was exposed to the CW laser for less than $5 \mathrm{~s}$. Reported illumination fluence values incorporate experimental exposure times. 


\section{Sample Characterization Using UV/Vis/NIR Spectrophotometry, pH Measurement, Zeta Potential, and DNA Labeling.}

UV-vis-NIR absorbance spectroscopy was conducted with a Jasco V-670 spectrophotometer using $1 \mathrm{~cm}$ path-length cuvettes (Eppendorf 952010069). The average power of the instrument excitation beam is $4 \mathrm{~mW}$ which forms roughly a $0.31 \mathrm{~cm}^{2}$ focal spot on the sample; $1 \mathrm{~s}$ is a typical exposure time for each $10 \mathrm{~nm}$ scanned. The extinction coefficients $\varepsilon_{\mathrm{DNA}}(910 \mathrm{~nm})=0.02254 \mathrm{~L} \cdot \mathrm{mg}^{-1} \cdot \mathrm{cm}^{-1}$ and $\varepsilon_{\mathrm{CMC}}(630 \mathrm{~nm})=0.036 \mathrm{~L} \cdot \mathrm{mg}^{-1} \cdot \mathrm{cm}$

${ }^{-1}$ were used for calculating DNA-SWCNT and CMC-SWCNT concentration, respectively.

A SevenCompact $\mathrm{pH} /$ Ion voltage meter (Mettler Toledo, Columbus, $\mathrm{OH}$ ) was connected to an InLab Micro $\mathrm{pH}$ electrode (Mettler Toledo, Columbus, $\mathrm{OH}$ ) with temperature adjustment. Reference $\mathrm{pH}_{\mathrm{a}}$ standard solutions (Sigma) were used for frequent calibration. Timedependent $\mathrm{pH}$ measurements used the LabXdirect software program (Mettler Toledo, Columbus, $\mathrm{OH})$. Briefly, $25 \mathrm{~mL}$ glass vials containing a Teflon stir rod contained SWCNTbuffer colloids. For well-plate experiments reported in the main text, "initial $\mathrm{pH}$ " electrode readings were taken in each well immediately after encapsulated-SWCNT was added into buffer. Samples used for spectroscopy were not exposed to the $\mathrm{pH}$ probe; a fresh sample series was prepared. $\mathrm{pH}$ of laser-exposed samples was measured in each well under ambient lighting.

To determine thymidine base primary amine functionalization, $0.3 \mathrm{mg} / \mathrm{mL}$ ssDNA $(\mathrm{GT})_{30}$ was mixed into $\mathrm{pH}$ buffer and left for $6 \mathrm{~h}$ exposed to ambient or $5 \% \mathrm{CO}_{2}$ atmosphere. After $6 \mathrm{~h}$, a final $1.75 \mathrm{mg} / \mathrm{mL}$ fluorescamine/DMSO solution (a 5:1 excess of fluorophore:amine) was incubated with ssDNA in buffer (60\% v/v DMSO/buffer solution). The solution was incubated for $15 \mathrm{~min}$ at room temperature. To control for $\mathrm{pH}$ effects on fluorescamine optical density, all final DMSO/buffers were adjusted to $\mathrm{pH} 3.0$ with the addition of $\mathrm{HCl}$ or an equivalent volume of deionized water. Reported $\mathrm{pH}$ values reflect measurements taken immediately after DNA was added into buffer. DNA-free fluorescamine blanks controlled for background signal. $\lambda_{\mathrm{ex}}: 400 \mathrm{~nm}, \lambda_{\mathrm{em}}: 480 \mathrm{~nm}$.

\section{Well-Plate Photoluminescence-Excitation Spectroscopy.}

For well-plate spectroscopy a continuous wave (CW) $730 \mathrm{~nm}$ diode laser with a maximum output power of $1 \mathrm{~W}$, or a SuperK Extreme supercontinuum laser connected to a variable bandpass filter (Varia, NKT Photonics), was focused through each sample with a 20× air objective (Olympus) below the stage of an inverted microscope (Olympus IX-71). A custom LabView (National Instruments) automation program was used for data acquisition. Emission was recorded from 915 to $1354 \mathrm{~nm}$. A $20 \mathrm{~nm}$ excitation bandwidth was used in all experiments. Exposure times were held constant within experiments. Light was collected with an IsoPlane SCT 320 spectrograph (Princeton Instruments, wavelength resolution 0.5$0.6 \mathrm{~nm}$ ) and recorded by a $-80{ }^{\circ} \mathrm{C}$ PioNIR InGaAs camera (Princeton Instruments). ${ }^{7}$

Working sample colloids (110-130 $\mu \mathrm{L})$ that contained a final SWCNT mass below 300 nanograms ( $\mathcal{\Omega} .7 \mu \mathrm{g} / \mathrm{mL}$, or mid-to-low nanomolar) were assayed in this work. For spectroscopy and $\mathrm{pH}$ assays, all well plates were incubated on the benchtop in the presence of room lighting (see Figure S6) for $15 \mathrm{~min}$ and then taken for spectroscopy in a dark room. 
For low $\mathrm{O}_{2}$ and high $\mathrm{CO}_{2}$ conditions, wells were incubated under a humidified atmosphere for $6 \mathrm{~h}$, double-sealed with Parafilm under atmosphere, and taken immediately for spectroscopy. Samples exposed to the CW laser were incubated alongside unexposed samples.

\section{Statistics, Analysis, and Software.}

Error bars in each figure represent standard deviation of $N=3$ technical replicates; in several figure panels error bars are too small to visualize. Spectral power, detector nonlinearity, and background correction were performed on all data using Matlab (R2012a). All emission/ absorption peaks representing various SWCNT diameters were fit with a Lorentzian function without deconvolution. OriginPro 9 was used to plot data. Adobe Illustrator CS6 was used to generate figures and diagrams. ChemBioDraw Ultra 13.0 was used to generate chemical structures. In most cases, reported data are normalized to highlight photoluminescence trends/behavior. Raw emission count differences between nonoverlapping data points ranged from $10^{3}$ to more than $10^{6}$ a.u.

\section{RESULTS}

\section{Spectroscopic Assay, Redox System, and Coating Sensitization Model.}

HiPco-produced SWCNTs were suspended with carboxymethyl cellulose (CMC) or singlestranded DNA (ssDNA) with the sequence (GT) 30 . SWCNT photoluminescence shows multiple emission peaks with intensities that depended on the $\mathrm{pH}$ of the buffer (Figure 1a and Figure S1, $730 \mathrm{~nm}$ continuous wave, CW, excitation). Distinct optical peaks were observed via absorbance spectroscopy (Figure $1 \mathrm{~b}$ and Figure S2). We note that the $730 \mathrm{~nm}$ $\mathrm{CW}$ excitation laser was within the SWCNT $\mathrm{S}_{22}$ absorbance bands $(500-850 \mathrm{~nm}$ ), but was not resonant with optical transitions of either the polymer coatings or the nanotube $\mathrm{S}_{11}$ NIR bands. Figure 1c describes the $\mathrm{pH}$ buffer system used to generate working CMC-/DNASWCNT suspensions. The reduction potential of each $\mathrm{pH}$ buffer alone or with added redox solute was measured with a platinum ORP electrode -0.15 molar $\mathrm{pH}$ buffers, containing the $\mathrm{O}_{2} / \mathrm{H}_{2} \mathrm{O}$ redox couple; hydrogen peroxide $\left(\mathrm{H}_{2} \mathrm{O}_{2}\right)$, a common oxidant; L-cysteine, a 2electron reductant; or ascorbate, a 1-electron reductant/oxidant. The reduction potentials of all buffers were largely linear across the $\mathrm{pH}$ range.

The $\mathrm{pH}$-dependent nanotube absorbance and emission were measured across the full $\mathrm{pH}$ range using the buffer system described above. Figure 2a reports the photoluminescence intensity behavior of Peak 3 (from Figure 1a), attributed to the $(9,4)$ species, of DNA- or CMC-SWCNTs diluted into $\mathrm{pH}$ buffers, incubated, and exposed to a $730 \mathrm{~nm}$ CW laser fluence of $12 \mathrm{~J} / \mathrm{cm}^{2}$. The $\mathrm{pH}$-dependent behavior of the nanotube photoluminescence differed between the two encapsulating polymers. Moreover, distinct changes in photoluminescence intensity appeared in the vicinities of specific $\mathrm{p} K_{\mathrm{a}}$ constants (proton ionization values, dotted lines) that correspond to known ionizable groups on either coating. For CMC-SWCNTs, one inflection point in intensity versus $\mathrm{pH}$ appeared at $\mathrm{pH} \sim 5$. The $\mathrm{p} K_{\mathrm{a}}$ of propionic acid, the sole ionizable group on CMC, is around $\mathrm{pH}$ 4.7. For DNA-SWCNT, similar phenomena were found, corresponding to several known $\mathrm{p} K_{\mathrm{a}}$ values of the DNA bases (Figure S3a). 
We further investigated whether the optical absorbance of the SWCNTs would exhibit coating and $\mathrm{pH}$-dependent features analogous to the photoluminescence response. UV-visNIR spectrophotometry in the 500-1400 nm range was used to measure DNA and CMCcoated-SWCNT absorbance in pH buffers (Figure 2b, Figure $\mathrm{S} 2$ ). The $\mathrm{S}_{11}$ absorbance behavior of Peak 3 species for DNA-SWCNT at $\mathrm{pH}>7$ roughly reflected photoluminescence behavior. On the other hand, CMC-SWCNT $\mathrm{S}_{11}$ absorbance sharply decreased at $\mathrm{pH}>7$, while emission tended to increase.

To analyze ionization ( $\mathrm{p} K_{\mathrm{a}}$-related features of the polymers, ${ }^{33}$ summarized in Figure S3a and the Supporting Information), we also plotted an energy diagram (Figure S3b,c) for relative energy alignment between electronic states in the nanotube and on the coatings; included are literature reported values for anodic (oxidation) potentials of the $(9,4)$ nanotube (Labels 1-2) and oxidation values for CMC and ssDNA coating constituents (Labels 3-11). In the Supporting Figure S3c, nearly all ground energy levels of the coating constituents are situated near or below the nanotube highest valence (sub-) band edge (Label 1) and in a few cases below the nanotube second valence (sub-) band edge (Label 2). The peak optical absorbance (ionization energy) of the CMC polymer was experimentally determined and plotted (Label 3*). Although not shown in the diagram, excited/ionized states for the ssDNA are near the SWCNT conduction bands.

The alignment diagram suggested reasonable overlap between SWCNT bands and CMC ionization states. Spectral peaks (Peaks 1-5) from CMC-SWCNT in the buffer assay were reported in Figure 2c. The $\mathrm{p} K_{\mathrm{a}}$ of the ionizable group on $\mathrm{CMC}$ (propionic acid, $\mathrm{pH} \sim 4.7$ ) was delineated by a photoluminescence feature near $\mathrm{pH} \sim 5$. This feature was most distinct for the shortest wavelength emitting species ( $\sim 990 \mathrm{~nm}$ ) yet disappeared for the longest wavelength emitters $(\sim 1280 \mathrm{~nm})$. To test whether the photoluminescence features were related to the SWCNT electrochemical bandgap $\left(\Delta E_{\text {electr }}\right)$, values from optical voltammetry of CMC-SWCNT ${ }^{46}$ were related to PL intensity in Figure 2d. In contrast, no direct correlation between $\mathrm{p} K_{\mathrm{a}}$-associated photoluminescence and calculated CMC charge density per length of nanotube (Figure S4a and Supporting Text) or CMC-SWCNT work function (Figure S4b) was found.

\section{Dependence of DNA-SWCNT Excitation-Emission Features on Laser Fluence, Semiconductor Bandgap, Excitation Energy, Temperature, and Chemical Redox.}

In contrast to the $\mathrm{CMC}$ polymer, the ssDNA coating contains several ionizable chemical groups with $\mathrm{pH}$-dependent electrochemical potentials. Photosensitization of this coating should depend on the electrochemical potential both of the SWCNT and of the electrolyte. We focus first on the dependence on fluence and nanotube bandgap. To assess $\mathrm{pH}$-dependent photoluminescence behavior as a function of laser fluence, DNA-SWCNT samples were exposed to the fluences varying by almost two decades (Figure 3a). pH-related photoluminescence features became stronger with increased fluence. A maximum between $\mathrm{pH} 1$ and 5 coincides with the third $\mathrm{p} K_{\mathrm{a}}$ value of guanine (p $K_{\mathrm{a}} \sim 3.9$ ). Another ssDNA p $K_{\mathrm{a}}$ related feature developed at $\mathrm{pH} 7-8$ (see arrows). Raw photoluminescence yields in three different $\mathrm{pH}$ buffer environments were plotted as a function of radiant fluence in Figure $3 \mathrm{~b}$, 
which showed an initial linear response, followed by a superlinear slope, and finally decay at ultrahigh fluence.

This nonlinear response at high fluence was evaluated with respect to nanotube optical bandgap. The response for clearly separated DNA-SWCNT emission peaks $(1,3$, and 4) from the buffer assay at maximal output $\left(20 \mathrm{~J} / \mathrm{cm}^{2}\right)$ fluence is shown in Figure $3 \mathrm{c}$ for large bandgap $(\sim 990 \mathrm{~nm})$, medium bandgap $(\sim 1130 \mathrm{~nm})$, or smaller bandgap $(\sim 1190 \mathrm{~nm})$ species. $\mathrm{p} K_{\mathrm{a}}$-related features were most prominent from the medium bandgap $(\sim 1130 \mathrm{~nm}) \mathrm{SWCNT}$ species.

Next, we investigated photochemical processes initiated by the SWCNT, as this could not be excluded due to the large power densities used in this study. ${ }^{62}$ Specifically, we focused on carbon side-wall reactivity as opposed to the coating reactivity. We measured photoluminescence at lower fluence $\left(0.3 \mathrm{~J} / \mathrm{cm}^{2}\right)$, outside of resonance with SWCNT excitation, as a function of $\mathrm{pH}$ (Figure 4a). The position of the laser excitation (bandwidth noted in the figure legend) was adjusted above or below the $\mathrm{S}_{22}$ optical resonance. Although minor differences were observed (arrows), results showed no major $\mathrm{p} K_{\mathrm{a}}$-dependent changes with respect to photon energies above (2.18-2.1 eV) or below (1.55-1.52 eV) the SWCNT excitation band.

We assessed $\mathrm{p} K_{\mathrm{a}}$-related photoluminescence dependence on the temperature (Figure $4 \mathrm{~b}$ ). Samples were kept on ice to lower the temperature of the DNA-SWCNT colloids to $4{ }^{\circ} \mathrm{C}$. We found that differences in $\mathrm{p} K_{\mathrm{a}}$-related photoluminescence features re-emerged in the colder temperature.

Next, we examined the role of the coating using two methods: adjusting the ssDNA (GT) base conjugation by changing the oligomer length and exposing the complexes to a singleelectron reductant/oxidant, ascorbate ${ }^{48}$ Figure $4 \mathrm{c}$ shows the effect of ssDNA polymer conjugation length on photoluminescence features for ssDNA of the order $(\mathrm{GT})_{6}<(\mathrm{GT})_{15}<$ $(\mathrm{GT})_{30}$. A broad flat photoluminescence plateau was observed for the shortest sequence, $(\mathrm{GT})_{6}$. This broad feature disappeared and transformed into several $\mathrm{p} K_{\mathrm{a}}$-related features as length increased (arrows). Additionally, an excess of the single-electron donor/acceptor ascorbate was introduced into each colloid. Results in Figure 4d showed that ascorbate abrogated the dip in DNA-SWCNT photoluminescence between $\mathrm{pH} 4$ and 6, as well as decreased photoluminescence above $\mathrm{pH} \sim 12$, similar to the curve for $(\mathrm{GT})_{6}$-SWCNT in Figure 4c. In conventional electrochemical studies, changes in SWCNT emission wavelength are also observed at extremes of applied voltage. ${ }^{45,47}$ The peak center wavelength exhibited a distinct shift from this redox experiment (Figure S5) (blue to red) and also showed coating $\mathrm{p} K_{\mathrm{a}}$-related features.

\section{Assay for Coating-Related $\mathrm{O}_{2} / \mathrm{H}_{2} \mathrm{O}$ Redox Reactivity in Colloid.}

We investigated the change in solution $\mathrm{pH}$ upon excitation with high laser fluence since a change in $\mathrm{pH}$ can result from photoelectrochemical reactions near the nanotube/coating. A micro $\mathrm{pH}$ electrode was used to measure the colloidal samples after room incubation (under ambient room lighting: less than $12 \mathrm{~mJ} / \mathrm{cm}^{2}$ ) (Figure S6) or after CW laser exposure (at 12 $\left.\mathrm{J} / \mathrm{cm}^{2}\right)$. Figure 5 a reports the change in buffer $\mathrm{pH}(\Delta \mathrm{pH})$ as a function of the initial $\mathrm{pH}$ 
measured after benchtop incubation of working DNA-SWCNT colloids (cf. Figure S7 for CMC-SWCNT). Positive $\triangle \mathrm{pH}$ values indicate alkalization, and negative values indicate acidification. The data show $\mathrm{pH}$ changes that are significant considering the buffering capacity was roughly $50 \mathrm{mM}$. Interestingly, for the reaction at high fluence $\left(12 \mathrm{~J} / \mathrm{cm}^{2}\right)$, the $\Delta \mathrm{pH}$ features correlated with coating ionization at the ssDNA $\mathrm{p} K_{\mathrm{a}}$ values (dashed lines). A background solution reaction under ambient lighting $\left(<12 \mathrm{~mJ} / \mathrm{cm}^{2}\right)$ was also present. More importantly, no measurable reaction was detected when colloids were protected from ambient light with tin foil (Figure S8).

We next investigated the change in solution $\mathrm{pH}$ after the addition of cysteine, a reductant, ${ }^{63}$ or hydrogen peroxide, an oxidant (Figure 5b). Alkalization was observed upon addition of cysteine for lower illumination fluence ( $\mathrm{pH} \sim 9-10)$ and a shift of the acidic maximum occured from $\mathrm{pH} \sim 3$ (without cysteine) to $\mathrm{pH} \sim 2$ (with cysteine). Upon introducing hydrogen peroxide, acidification, $\mathrm{pH} \sim 10$, occurred both under ambient and intense illumination. After redox treatment, $\mathrm{p} K_{\mathrm{a}}$-related photoluminescence behavior was similar to that of the original samples (Figure 5c) with the exception of cysteine-treated colloids at a $\mathrm{pH}$ around the cysteine $\mathrm{p} K_{\mathrm{a}}$. Here, the low-pH PL peak was shifted to more acidic values and the alkaline PL maximum was flattened. Hydrogen peroxide did not attenuate photoluminescence, except under highly oxidizing conditions below a $\mathrm{pH}$ of 3 . Additional data presented in Figure S9, wherein carboxylate oxygens were introduced onto the coating, show correlation between alkalization/acidification and emission intensity.

\section{DISCUSSION}

This work examined carbon nanotube optical properties via optical voltammetry-like measurements conducted in a solution/colloidal phase. We investigated whether the $\pi$-rich electronic system and redox-active moieties of the coatings on semiconducting nanotubes play an active role in solvated-stage photoelectrochemistry of the complexes, similar to photocharge characterized through ultrafast spectroscopic studies, ${ }^{33}$ without applying any potential to solution or connecting tube to electrode. A classic semiconductor photoelectrochemical model ${ }^{64-66}$ was considered in this context. Photoelectrochemical behavior was shown for SWCNTs coated by cationic hydrocarbon in the presence of an appropriate redox couple, ${ }^{2}$ and SWCNTs were found to promote reactions through the coating; $38,40,41$ however, we did not find evidence for direct involvement of the coating during excitation.

Under large illumination fluences, nonlinear optical processes may occur in SWCNTs; for example, a photoionization of excited states (cf. Figure 2a, Figure 2b, and Figure S3). We note that excitation fluences similar to those used in this work are routinely employed in laboratories; given that ca. $0.03 \mu \mathrm{J} / \mathrm{cm}^{2}$ excitation was shown to be sufficient to promote photogenerated potential on polymer-coated SWCNTs, ${ }^{22,24}$ this work's findings may be relevant to SWCNT characterization in ambient conditions.

The use of a linear redox buffer (Figure 1) was critical to unambiguously correlate photoluminescence and absorbance variation (Figure 2) to coating ionization, specifically, the redox active components of the polymer (Figure S3a). Since $\mathrm{p} K_{\mathrm{a}}$-related 
photoluminescence features were observed at all laser exposures used in this work, the photogenerated steady-state population density on the nanotube was likely responsible for the reactivity.

Polymeric systems like ssDNA can promote (catalyze) charge transfer between a photosensitizer and redox solute. ${ }^{61}$ Photosensitization requires the electrochemical potential of interacting components to be aligned (Figure S3c). A dependence of these results on the bandgap of the SWCNT (Figure $2 \mathrm{c}-\mathrm{d}, 3 \mathrm{c}$ ) supports the idea that sensitization of the encapsulation depends on the interacting energies between SWCNT and coating; however, data also suggest that an optimal overlap exists between particular SWCNT bandgap energies and the redox states on the coating. Interestingly, we found that the ground-state absorption behavior resembled photoluminescence behavior only for the DNA-SWCNT. It is possible that the ionizable states on the CMC polymer do not overlap the SWCNT bands to the same degree under similar redox conditions. While the charge state of the coating was reported to influence the redox phenomena observed, ${ }^{48}$ in this work we showed evidence that this behavior can be attributed to ionizable $(\pi)$ groups on the coating.

In earlier photochemical doping experiments, covalent modifications were found to be dependent on excitation energy and independent of temperature. ${ }^{62}$ In this work, (Figure 4ab) we found a dependence on the solute temperature while variations of excitation energy around resonance did not show an appreciable effect. The reactive nature of the coating, rather than of the SWCNT itself, was also suggested by a general lack of photoluminescence quenching after $\mathrm{H}_{2} \mathrm{O}_{2}$ treatment, as well as a lack of appreciable changes to the $\mathrm{p} K_{\mathrm{a}}$-related optical features. Furthermore, coating charge density and nanotube work function trends (Figure S4) suggested that the $\mathrm{pH} / \mathrm{p} K_{\mathrm{a}}$-related photoluminescence features were not directly related to classic charge separation (doping) between coating and nanotube. Rather, emission behaviors may be a result of electronic hybridization effects. ${ }^{33,67}$ These effects would explain spectroscopic (intensity and wavelength) changes ${ }^{68}$ often discussed in relation to the coating's electronic conjugation (Figures 4c-d, S5).

Colloidal redox phenomena are commonly observed when SWCNT are exposed to standard illumination sources. ${ }^{38,40,41,60}$ Detection of solution reactivity ( $\Delta \mathrm{pH}$, Figures 5 and $\mathrm{S} 7$ ) following the coating's $\mathrm{p} K_{\mathrm{a}}$ supports a photosensitization scheme in which the SWCNT excited state is sensitive to modification of the reduction/oxidation environment, including the addition of ionizable groups to the coating (Figure S9). We further discuss one implication for routine characterization in the Supporting Information. Finally, it will be important to investigate these optical phenomena using enriched/separated SWCNT samples, when available. Similarly, full excitation-emission mapping may be used to assess spectral contributions from other SWCNT species if longer exposure times and offresonance excitation are acceptable.

\section{CONCLUSIONS}

We found a distinct optical response of nanotubes exposed to aqueous redox buffers that mimics a nanotube response to applied electrochemical potentials. While the photoluminescence response to a gate voltage depends on the redox potential of the 
nanotube, here we found that a similar optical response in aqueous suspension can occur in the absence of applied voltage; we refer to this phenomenon as optical voltammetry. The experimental results were highly dependent on the chemistry of the encapsulating polymer, as evidenced with two anionic polyelectrolyte coatings. Nanotube steady-state photoluminescence and absorbance responded to a linear $\mathrm{O}_{2} / \mathrm{H}_{2} \mathrm{O}$ redox buffer nonmonotonically. Correlation to ionization $\left(\mathrm{p} K_{\mathrm{a}}\right)$ properties of the coating suggest that the nanotube acts as a photosensitizer (while direct carbon sidewall reactivity was discounted). Coating- and illumination fluence-dependent $\mathrm{O}_{2} / \mathrm{H}_{2} \mathrm{O}$ reactivity was detected through $\mathrm{pH}$ changes in colloid. Therefore, ionizable coating components may be major sites of SWCNT excited-state interactions. This work also suggests that nonlinear processes at relatively large illumination fluences, employed in routine spectroscopic assays, can initiate electrochemical reactions on SWCNT/coating complexes. The reversibility of coating electronic transformations by SWCNT excited states is a nascent area; further studies on the identity of the photoexcitations that contributed to these findings are warranted. Such information may lead to improved control of exciton recombination for sensing, photonics, and photovoltaic applications.

\title{
Supplementary Material
}

Refer to Web version on PubMed Central for supplementary material.

\section{ACKNOWLEDGMENTS}

\begin{abstract}
This work was supported in part by the National Science Foundation CAREER Award (1752506), the NIH New Innovator Award (DP2-HD075698), NIDDK (R01DK114321-01A1), NCI (R01CA215719-02), the Cancer Center Support Grant (P30 CA008748), the Pershing Square Sohn Cancer Research Alliance, the Honorable Tina Brozman Foundation for Ovarian Cancer Research, the Expect Miracles Foundation Financial Services Against Cancer, the Anna Fuller Fund, the Louis V. Gerstner Jr. Young Investigator's Fund, the Frank A. Howard Scholars Program, MSK's Cycle for Survival's Equinox Innovation Award in Rare Cancers, the Alan and Sandra Gerry Metastasis Research Initiative, Mr. William H. Goodwin and Mrs. Alice Goodwin and the Commonwealth Foundation for Cancer Research, the Experimental Therapeutics Center, the Imaging \& Radiation Sciences Program, and the Center for Molecular Imaging and Nanotechnology of Memorial Sloan Kettering Cancer Center. D.R. was supported in part by the American Cancer Society Roaring Fork Valley Postdoctoral Fellowship (PF-13-388801TBG) as well as a National Science Foundation CAREER Award (1844536); S.V.R. acknowledges NSF support (ECCS-1509786). The authors thank Karla H. Gioia, Januka Budhathoki-Uprety, Rahul V. Rao-Pothuraju, Peter Schnatz, Richard Martel, and Justin R. Cross of the Donald B. and Catherine C. Marron Cancer Metabolism Center of Memorial Sloan Kettering Cancer Center for discussions and technical assistance.
\end{abstract}

\section{REFERENCES}

(1). O’Connell MJ; Bachilo SM; Huffman CB; Moore VC; Strano MS; Haroz EH; Rialon KL; Boul PJ; Noon WH; Kittrell C; et al. Band Gap Fluorescence from Individual Single-Walled Carbon Nanotubes. Science (Washington, DC, U. S.) 2002, 297, 593-6.

(2). Barazzouk S; Hotchandani S; Vinodgopal K; Kamat PV Single-Wall Carbon Nanotube Films for Photocurrent Generation. A Prompt Response to Visible-Light Irradiation. J. Phys. Chem. B 2004, 108, 17015-17018.

(3). Barone PW; Baik S; Heller DA; Strano MS Near-Infrared Optical Sensors Based on Single-Walled Carbon Nanotubes. Nat. Mater 2004, 4, 86-92. [PubMed: 15592477]

(4). Heller DA; Baik S; Eurell TE; Strano MS Single-Walled Carbon Nanotube Spectroscopy in Live Cells: Towards Long-Term Labels and Optical Sensors. Adv. Mater 2005, 17, 2793-2799.

(5). Heller DA; Pratt GW; Zhang J; Nair N; Hansborough AJ; Boghossian AA; Reuel NF; Barone PW; Strano MS Peptide Secondary Structure Modulates Single-Walled Carbon Nanotube 
Fluorescence as a Chaperone Sensor for Nitroaromatics. Proc. Natl. Acad. Sci. U. S. A 2011, 108, 8544-8549. [PubMed: 21555544]

(6). Zhang J; Landry MP; Barone PW; Kim JH; Lin S; Ulissi ZW; Lin D; Mu B; Boghossian AA; Hilmer AJ; et al. Molecular Recognition Using Corona Phase Complexes Made of Synthetic Polymers Adsorbed on Carbon Nanotubes. Nat. Nanotechnol 2013, 8, 959-968. [PubMed: 24270641]

(7). Roxbury D; Jena PV; Shamay Y; Horoszko CP; Heller DA Cell Membrane Proteins Modulate the Carbon Nanotube Optical Bandgap Via Surface Charge Accumulation. ACS Nano 2016, 10, 499. [PubMed: 26654246]

(8). Jacobs CB; Peairs MJ; Venton BJ Review: Carbon Nanotube Based Electrochemical Sensors for Biomolecules. Anal. Chim. Acta 2010, 662, 105-127. [PubMed: 20171310]

(9). Lin C-W; Bachilo SM; Vu M; Beckingham KM; Bruce Weisman R Spectral Triangulation: A 3d Method for Locating Single-Walled Carbon Nanotubes in Vivo. Nanoscale 2016, 8, 1034810357. [PubMed: 27140495]

(10). Harvey JD; Jena PV; Baker HA; Zerze GH; Williams RM; Galassi TV; Roxbury D; Mittal J; Heller DA A Carbon Nanotube Reporter of Microrna Hybridization Events in Vivo. Nature Biomedical Engineering 2017, 1, 0041.

(11). Welsher K; Sherlock SP; Dai H Deep-Tissue Anatomical Imaging of Mice Using Carbon Nanotube Fluorophores in the Second near-Infrared Window. Proc. Natl. Acad. Sci. U. S. A 2011, 108, 8943-8948. [PubMed: 21576494]

(12). Kumamoto Y; Yoshida M; Ishii A; Yokoyama A; Shimada T; Kato YK Spontaneous Exciton Dissociation in Carbon Nanotubes. Phys. Rev. Lett 2014, 112, 117401. [PubMed: 24702413]

(13). Wang F; Dukovic G; Knoesel E; Brus LE; Heinz TF Observation of Rapid Auger Recombination in Optically Excited Semiconducting Carbon Nanotubes. Phys. Rev. B: Condens. Matter Mater. Phys 2004, 70, 241403.

(14). Gabor NM; Zhong Z; Bosnick K; Park J; McEuen PL Extremely Efficient Multiple ElectronHole Pair Generation in Carbon Nanotube Photodiodes. Science (Washington, DC, U. S.) 2009, 325, 1367-1371.

(15). Kanemitsu Y Multiple Exciton Generation and Recombination in Carbon Nanotubes and Nanocrystals. Acc. Chem. Res 2013, 46, 1358-1366. [PubMed: 23421584]

(16). Santos SM; Yuma B; Berciaud S; Shaver J; Gallart M; Gilliot P; Cognet L; Lounis B All-Optical Trion Generation in Single-Walled Carbon Nanotubes. Phys. Rev. Lett 2011, 107, 187401. [PubMed: 22107671]

(17). Yuma B; Berciaud S; Besbas J; Shaver J; Santos S; Ghosh S; Weisman RB; Cognet L; Gallart M; Ziegler M; et al. Biexciton, Single Carrier, and Trion Generation Dynamics in Single-Walled Carbon Nanotubes. Phys. Rev. B 2013, 87, 205412.

(18). Park J; Deria P; Olivier J-H; Therien MJ Fluence-Dependent Singlet Exciton Dynamics in Length-Sorted Chirality-Enriched Single-Walled Carbon Nanotubes. Nano Lett. 2014, 14, 504 511. [PubMed: 24329134]

(19). Gadermaier C; Menna E; Meneghetti M; Kennedy WJ; Vardeny ZV; Lanzani G Long-Lived Charged States in Single-Walled Carbon Nanotubes. Nano Lett. 2006, 6, 301-305. [PubMed: 16464054]

(20). Sciascia C; Crochet J; Hertel T; Lanzani G Long Lived Photo Excitations in (6, 5) Carbon Nanotubes. Eur. Phys. J. B 2010, 75, 115-120.

(21). Beard MC; Blackburn JL; Heben MJ Photogenerated Free Carrier Dynamics in Metal and Semiconductor Single-Walled Carbon Nanotube Films. Nano Lett. 2008, 8, 4238-4242. [PubMed: 19367928]

(22). Park J; Reid OG; Blackburn JL; Rumbles G Photoinduced Spontaneous Free-Carrier Generation in Semiconducting Single-Walled Carbon Nanotubes. Nat. Commun 2015, 6, No. 8809.

(23). Soavi G; Scotognella F; Brida D; Hefner T; Späth F; Antognazza MR; Hertel T; Lanzani G; Cerullo G Ultrafast Charge Photogeneration in Semiconducting Carbon Nanotubes. J. Phys. Chem. C 2013, 117, 10849-10855. 
(24). Soavi G; Scotognella F; Viola D; Hefner T; Hertel T; Cerullo G; Lanzani G High Energetic Excitons in Carbon Nanotubes Directly Probe Charge-Carriers. Sci. Rep 2015, 5, 9681. [PubMed: 25959462]

(25). Xiao YF; Nhan TQ; Wilson MWB; Fraser JM Saturation of the Photoluminescence at FewExciton Levels in a Single-Walled Carbon Nanotube under Ultrafast Excitation. Phys. Rev. Lett 2010, 104, 017401. [PubMed: 20366391]

(26). Moritsubo S; Murai T; Shimada T; Murakami Y; Chiashi S; Maruyama S; Kato YK Exciton Diffusion in Air-Suspended Single-Walled Carbon Nanotubes. Phys. Rev. Lett 2010, 104, 247402. [PubMed: 20867335]

(27). Matsuda K; Inoue T; Murakami Y; Maruyama S; Kanemitsu Y Exciton Dephasing and Multiexciton Recombinations in a Single Carbon Nanotube. Phys. Rev. B: Condens. Matter Mater. Phys 2008, 77, 033406.

(28). Mohite AD; Gopinath P; Shah HM; Alphenaar BW Exciton Dissociation and Stark Effect in the Carbon Nanotube Photocurrent Spectrum. Nano Lett. 2008, 8, 142-146. [PubMed: 18047383]

(29). Yoshida M; Kumamoto Y; Ishii A; Yokoyama A; Kato YK Stark Effect of Excitons in Individual Air-Suspended Carbon Nanotubes. Appl. Phys. Lett 2014, 105, 161104.

(30). Kazaoui S; Cook S; Izard N; Murakami Y; Maruyama S; Minami N Photocurrent Quantum Yield of Semiconducting Carbon Nanotubes: Dependence on Excitation Energy and Exciton Binding Energy. J. Phys. Chem. C 2014, 118, 18059-18063.

(31). Perebeinos V; Avouris P Exciton Ionization, Franz-Keldysh, and Stark Effects in Carbon Nanotubes. Nano Lett. 2007, 7, 609-613. [PubMed: 17261074]

(32). Freitag M; Steiner M; Naumov A; Small JP; Bol AA; Perebeinos V; Avouris P Carbon Nanotube Photo- and Electroluminescence in Longitudinal Electric Fields. ACS Nano 2009, 3, 3744-3748. [PubMed: 19928934]

(33). Kahmann S; Salazar Rios JM; Zink M; Allard S; Scherf U; dos Santos MC; Brabec CJ; Loi MA Excited-State Interaction of Semiconducting Single-Walled Carbon Nanotubes with Their Wrapping Polymers. J. Phys. Chem. Lett 2017, 8, 5666-5672. [PubMed: 29099192]

(34). Satishkumar BC; Brown LO; Gao Y; Wang C-C; Wang H-L; Doorn SK Reversible Fluorescence Quenching in Carbon Nanotubes for Biomolecular Sensing. Nat. Nanotechnol 2007, 2, 560-564. [PubMed: 18654368]

(35). O'Connell MJ; Eibergen EE; Doorn SK Chiral Selectivity in the Charge-Transfer Bleaching of Single-Walled Carbon-Nanotube Spectra. Nature materials 2005, 4, 412-8. [PubMed: 15821741]

(36). Zheng M; Diner BA Solution Redox Chemistry of Carbon Nanotubes. J. Am. Chem. Soc 2004, 126, 15490-15494. [PubMed: 15563177]

(37). Joshi A; Punyani S; Bale SS; Yang H; Borca-Tasciuc T; Kane RS Nanotube-Assisted Protein Deactivation. Nat. Nanotechnol 2008, 3, 41-45. [PubMed: 18654449]

(38). Chen C-Y; Jafvert CT The Role of Surface Functionalization in the Solar Light-Induced Production of Reactive Oxygen Species by Single-Walled Carbon Nanotubes in Water. Carbon 2011, 49, 5099-5106.

(39). Hsieh H-S; Wu R; Jafvert CT Light-Independent Reactive Oxygen Species (Ros) Formation through Electron Transfer from Carboxylated Single-Walled Carbon Nanotubes in Water. Environ. Sci. Technol 2014, 48, 11330-11336. [PubMed: 25171301]

(40). Hou W-C; BeigzadehMilani S; Jafvert CT; Zepp RG Photoreactivity of Unfunctionalized SingleWall Carbon Nanotubes Involving Hydroxyl Radical: Chiral Dependency and Surface Coating Effect. Environ. Sci. Technol 2014, 48, 3875-3882. [PubMed: 24628431]

(41). Hsieh H-S; Jafvert CT Reactive Oxygen Species Generation and Dispersant-Dependent Electron Transfer through Single-Walled Carbon Nanotubes in Water. Carbon 2015, 89, 361-371.

(42). Kunai Y; Liu AT; Cottrill AL; Koman VB; Liu P; Kozawa D; Gong X; Strano MS Observation of the Marcus Inverted Region of Electron Transfer from Asymmetric Chemical Doping of Pristine (N,M) Single-Walled Carbon Nanotubes. J. Am. Chem. Soc 2017, 139, 15328-15336. [PubMed: 28985673]

(43). Frank O; Kavan L; Green AA; Hersam MC; Dunsch L In-Situ Vis/Nir Spectroelectrochemistry of Single-Walled Carbon Nanotubes Enriched with (6,5) Tubes. Phys. Status Solidi B 2008, 245, 2239-2242. 
(44). Hong L; Mouri S; Miyauchi Y; Matsuda K; Nakashima N Redox Properties of a Single $(7,5)$ Single-Walled Carbon Nanotube Determined by an in Situ Photoluminescence Spectroelectrochemical Method. Nanoscale 2014, 6, 12798-12804. [PubMed: 25226303]

(45). Schafer S; Cogan NM; Krauss TD Spectroscopic Investigation of Electrochemically Charged Individual (6,5) Single-Walled Carbon Nanotubes. Nano Lett. 2014, 14, 3138-44. [PubMed: 24797608]

(46). Tanaka Y; Hirana Y; Niidome Y; Kato K; Saito S; Nakashima N Experimentally Determined Redox Potentials of Individual (N,M) Single-Walled Carbon Nanotubes. Angew. Chem., Int. Ed 2009, 48, 7655-9.

(47). Hartleb H; Späth F; Hertel T Evidence for Strong Electronic Correlations in the Spectra of GateDoped Single-Wall Carbon Nanotubes. ACS Nano 2015, 9, 10461. [PubMed: 26381021]

(48). Polo E; Kruss S Impact of Redox-Active Molecules on the Fluorescence of Polymer-Wrapped Carbon Nanotubes. J. Phys. Chem. C 2016, 120, 3061.

(49). Bergonzini G; Cassani C; Wallentin C-J Acyl Radicals from Aromatic Carboxylic Acids by Means of Visible-Light Photoredox Catalysis. Angew. Chem. Int. Ed 2015, 54, 14066-14069.

(50). Jovanovic SV; Simic MG One-Electron Redox Potentials of Purines and Pyrimidines. J. Phys. Chem 1986, 90, 974-978.

(51). Cadet J; Wagner JR; Shafirovich V; Geacintov NE One-Electron Oxidation Reactions of Purine and Pyrimidine Bases in Cellular DNA. Int. J. Radiat. Biol 2014, 90, 423-32. [PubMed: 24369822]

(52). Kawai K; Takada T; Nagai T; Cai X; Sugimoto A; Fujitsuka M; Majima T Long-Lived ChargeSeparated State Leading to DNA Damage through Hole Transfer. J. Am. Chem. Soc 2003, 125, 16198-16199. [PubMed: 14692755]

(53). Steenken S; Jovanovic SV How Easily Oxidizable Is DNA? One-Electron Reduction Potentials of Adenosine and Guanosine Radicals in Aqueous Solution. J. Am. Chem. Soc 1997, 119, 617-618.

(54). Psciuk BT; Schlegel HB Computational Prediction of One-Electron Reduction Potentials and Acid Dissociation Constants for Guanine Oxidation Intermediates and Products. J. Phys. Chem. B 2013, 117, 9518-9531. [PubMed: 23875631]

(55). Crespo-Hernández CE; Close DM; Gorb L; Leszczynski J Determination of Redox Potentials for the Watson-Crick Base Pairs, DNA Nucleosides, and Relevant Nucleoside Analogues. J. Phys. Chem. B 2007, 111, 5386-5395. [PubMed: 17447808]

(56). Lewis FD; Liu J; Zuo X; Hayes RT; Wasielewski MR Dynamics and Energetics of Single-Step Hole Transport in DNA Hairpins. J. Am. Chem. Soc 2003, 125, 4850-4861. [PubMed: 12696904]

(57). Yoo KH; Ha DH; Lee JO; Park JW; Kim J; Kim JJ; Lee HY; Kawai T; Choi HY Electrical Conduction through Poly(Da)-Poly(Dt) and Poly(Dg)-Poly(Dc) DNA Molecules. Phys. Rev. Lett 2001, 87, 198102. [PubMed: 11690458]

(58). Petersen EJ; Tu X; Dizdaroglu M; Zheng M; Nelson BC Protective Roles of Single-Wall Carbon Nanotubes in Ultrasonication-Induced DNA Base Damage. Small 2013, 9, 205-208. [PubMed: 22987483]

(59). Satishkumar BC; Brown LO; Gao Y; Wang CC; Wang HL; Doorn SK Reversible Fluorescence Quenching in Carbon Nanotubes for Biomolecular Sensing. Nat. Nanotechnol 2007, 2, 560-4. [PubMed: 18654368]

(60). Chiu CF; Saidi WA; Kagan VE; Star A Defect-Induced near-Infrared Photoluminescence of Single-Walled Carbon Nanotubes Treated with Polyunsaturated Fatty Acids. J. Am. Chem. Soc 2017, 139, 4859-4865. [PubMed: 28288512]

(61). Travascio P; Li Y; Sen D DNA-Enhanced Peroxidase Activity of a DNA-Aptamer-Hemin Complex. Chem. Biol 1998, 5, 505-17. [PubMed: 9751647]

(62). Wu X; Kim M; Kwon H; Wang Y Photochemical Creation of Fluorescent Quantum Defects in Semiconducting Carbon Nanotube Hosts. Angew. Chem., Int. Ed 2018, 57, 648-653.

(63). Kurnosov NV; Leontiev VS; Linnik AS; Karachevtsev VA Influence of Cysteine Doping on Photoluminescence Intensity from Semiconducting Single-Walled Carbon Nanotubes. Chem. Phys. Lett 2015, 623, 51-54. 
(64). Memming R Charge Transfer Processes at the Semiconductor-Liquid Interface In Semiconductor Electrochemistry; Wiley-VCH Verlag GmbH \& Co. KGaA: Weinheim, Germany, 2015; pp 169_ 266.

(65). Memming R Photoreactions at Semiconductor Particles In Semiconductor Electrochemistry; Wiley-VCH Verlag GmbH \& Co. KGaA: Weinheim, Germany, 2015; pp 295-342.

(66). Memming R Electron Transfer Processes between Excited Molecules and Semiconductor Electrodes In Semiconductor Electrochemistry; Wiley-VCH Verlag GmbH \& Co. KGaA: Weinheim, Germany 2015; pp 343-377.

(67). Milko M; Puschnig P; Blondeau P; Menna E; Gao J; Loi MA; Draxl C Evidence of Hybrid Excitons in Weakly Interacting Nanopeapods. J. Phys. Chem. Lett 2013, 4, 2664-2667. [PubMed: 23991266]

(68). Ito M; Ito Y; Nii D; Kato H; Umemura K; Homma Y The Effect of DNA Adsorption on Optical Transitions in Single Walled Carbon Nanotubes. J. Phys. Chem. C 2015, 119, 21141-21145. 

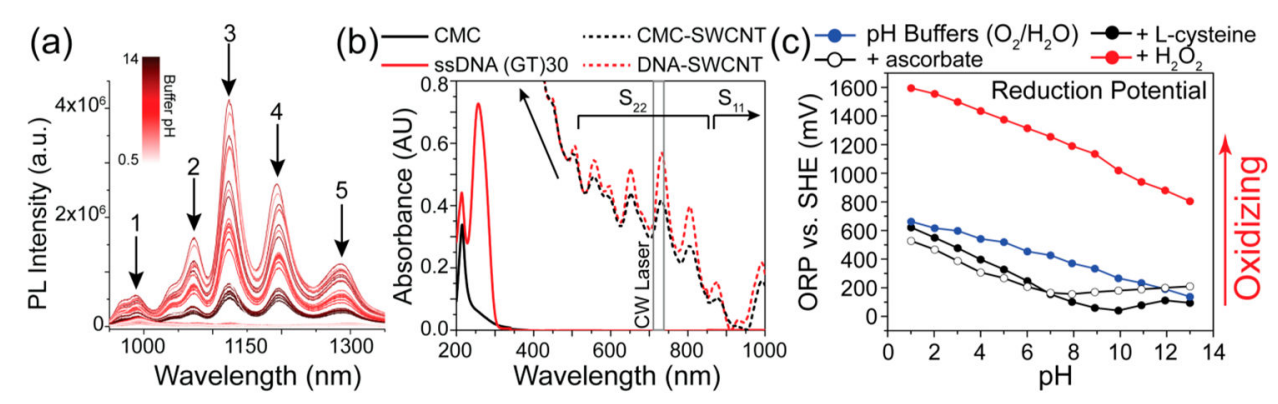

Figure 1.

(a) Representative steady-state photoluminescence-excitation spectra $\left(\lambda_{\mathrm{ex}}: 730 \mathrm{~nm}\right)$ of DNA-SWCNT in different pH-controlled buffers. (b) Steady-state absorbance of polymer coatings alone or polymer coated-SWCNTs. Vertical lines delimit the CW laser excitation used in this work's experiments. (c) Oxidation-reduction potential (ORP) probe measurement of each $\mathrm{pH}$ buffer alone or with $1 \mathrm{mM}$ of the indicated reductant/oxidant. 
(a)

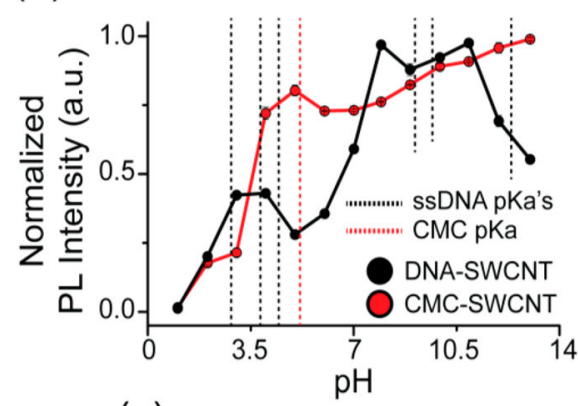

(c)

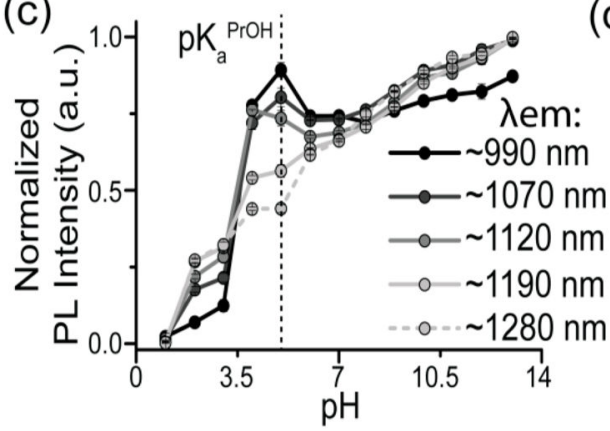

(b)

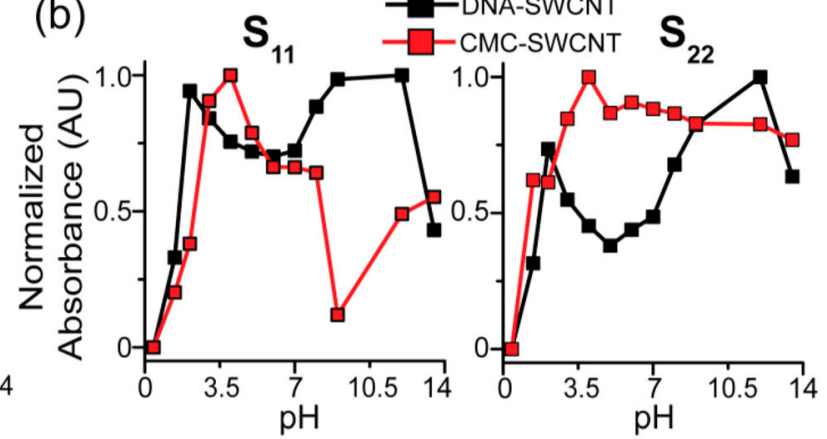

(d)

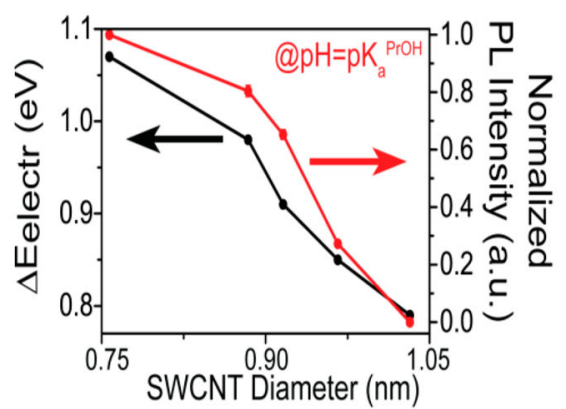

Figure 2.

(a) Normalized photoluminescence intensity of carbon nanotubes coated by CMC and DNA. Emission Peak 3, attributed to the $(9,4)$ nanotube species, is shown; vertical lines denote the $\mathrm{p} K_{\mathrm{a}}$ constants of coating constituents. (b) Normalized absorbance intensity of the $\mathrm{S}_{11}$ (left panel) or $\mathrm{S}_{22}$ (right panel) transition arising from Peak 3 species in the $\mathrm{pH}$ assay. (c) Normalized photoluminescence intensity of CMC-SWCNT from the $\mathrm{pH}$ assay; Peak 1 (990 $\mathrm{nm})$ to Peak $5(1280 \mathrm{~nm})$. The CMC propionic acid (PrOH) $\mathrm{p} K_{\mathrm{a}}$ is indicated. (d)

Electrochemical bandgap $\left(\Delta E_{\text {electr }}\right)$ versus nanotube diameter, compared to diameterdependent photoluminescence from CMC-SWCNT in $\mathrm{pH}=5$ buffer. 
(a)

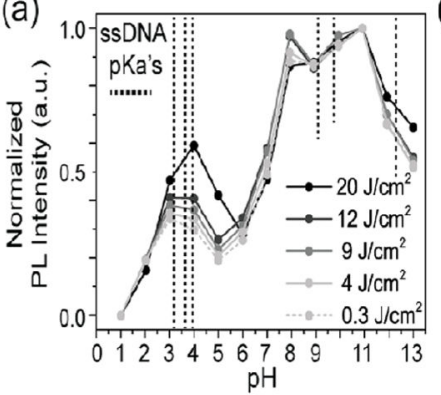

(b)

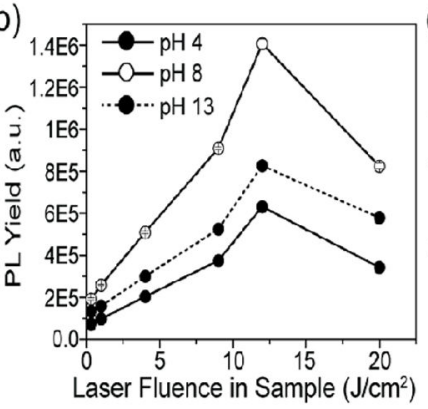

(c)

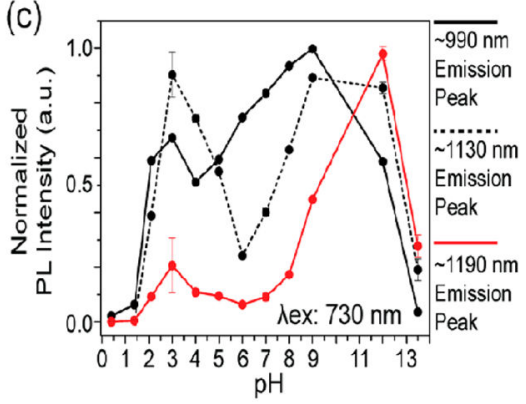

Figure 3.

(a) Steady-state photoluminescence from the DNA-SWCNT peak $1130 \mathrm{~nm}$ (Peak 3, $\lambda_{\text {ex }}$ : $730 \mathrm{~nm}$ ) as a function of buffer $\mathrm{pH}$ after the laser fluence in the sample was changed (see legend). Vertical lines indicate the $\mathrm{p} K_{\mathrm{a}}$ 's of the ssDNA coating. (b) Raw/absolute photoluminescence from (a), as a function of $\mathrm{CW}$ laser fluence, for three $\mathrm{pH}$ environments. (c) Steady-state photoluminescence, as in (a), after excitation with $20 \mathrm{~J} / \mathrm{cm}^{2}$. Three diameterrelated emission peaks are shown. 
(a)

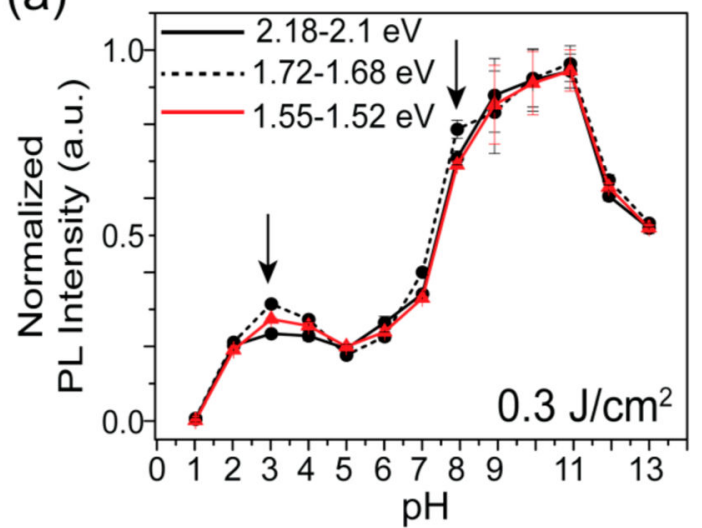

(c)

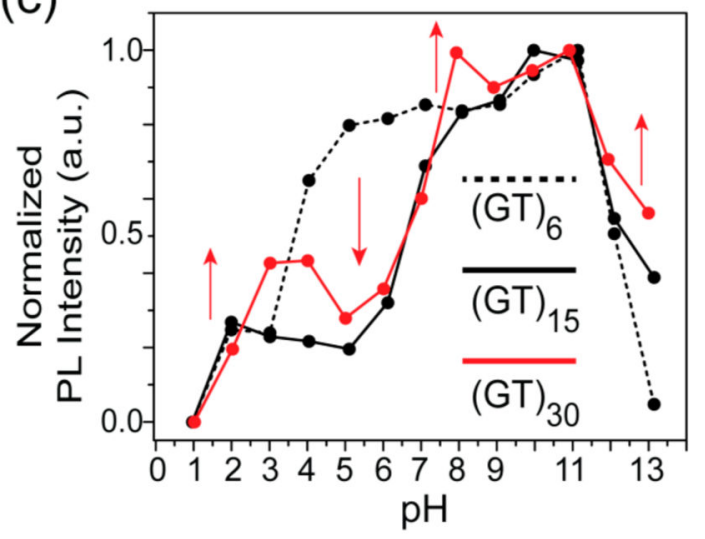

(b)

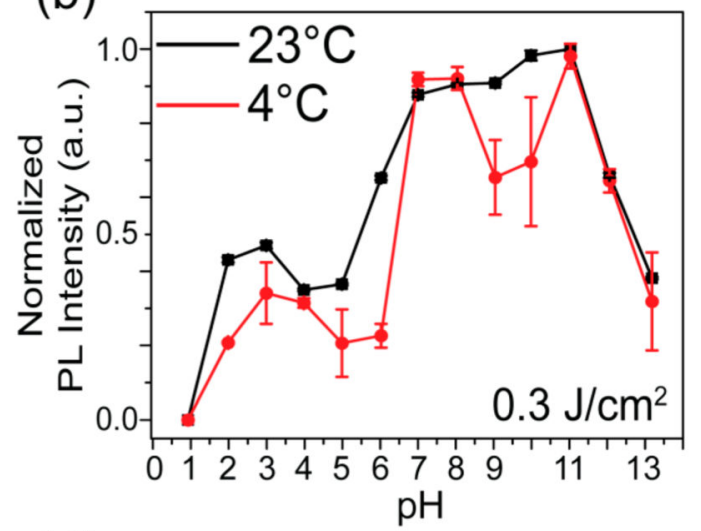

(d)

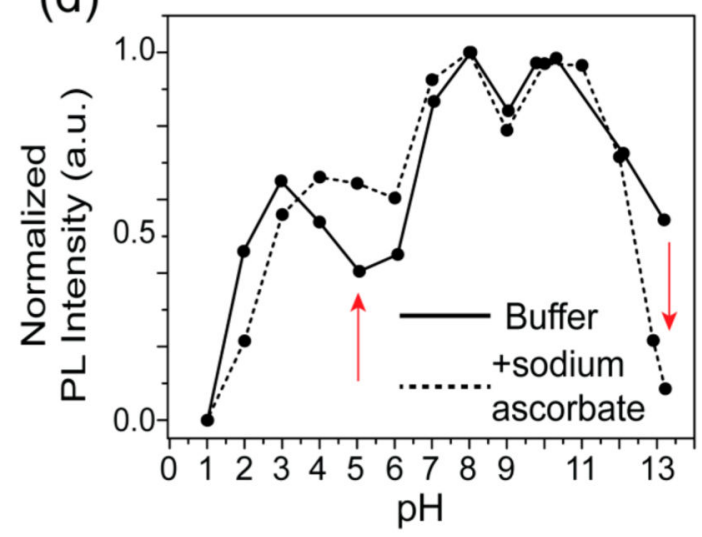

Figure 4.

(a) Steady-state photoluminescence from the DNA-SWCNT peak 1130 nm (Peak 3), as a function of buffer $\mathrm{pH}$, upon excitation with the $\mathrm{CW}$ laser energies listed in the legend (bandwidth included). Arrows reference the text. (b) Steady-state photoluminescence from the DNA-SWCNT peak 1130 nm (Peak 3), as a function of buffer $\mathrm{pH}$, after samples were incubated at room temperature $\left(23^{\circ} \mathrm{C}\right)$ or at $4{ }^{\circ} \mathrm{C}$. (c) Steady-state photoluminescence from the DNA-SWCNT peak $\sim 1130 \mathrm{~nm}$ (Peak 3), as a function of buffer $\mathrm{pH}$, when SWCNT were prepared using the ssDNA repeat lengths listed. Arrows reference the text. CW laser fluence in the sample was $20 \mathrm{~J} / \mathrm{cm}^{2}$. (d) Steady-state photoluminescence from the DNA-SWCNT peak $\sim 1130 \mathrm{~nm}$ (Peak 3), as a function of buffer $\mathrm{pH}$, with or without $1 \mathrm{mM}$ ascorbate. Arrows reference the text. CW laser fluence in the sample was $20 \mathrm{~J} / \mathrm{cm}^{2}$. 

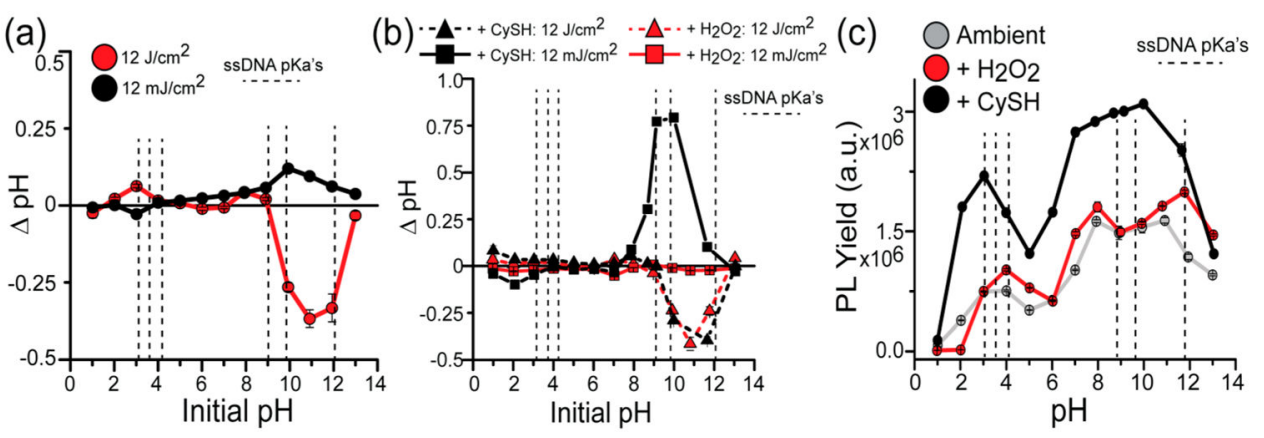

Figure 5.

(a) Change in solution $\mathrm{pH}(\Delta \mathrm{pH})$ as a function of starting $\mathrm{pH}$ for DNA-SWCNT exposed to ambient illumination $\left(12 \mathrm{~mJ} / \mathrm{cm}^{2}\right)$ or the $\mathrm{CW}$ laser $\left(12 \mathrm{~J} / \mathrm{cm}^{2}\right)$. Vertical lines are the ssDNA coating $\mathrm{p} K_{\mathrm{a}}$ 's. (b) As in (a) after $1 \mathrm{mM}$ cysteine $(\mathrm{CySH})$ or hydrogen peroxide $\left(\mathrm{H}_{2} \mathrm{O}_{2}\right)$ was added to each $\mathrm{pH}$ buffer. Vertical lines are the ssDNA coating $\mathrm{p} K_{\mathrm{a}}$ 's. (c) Steady-state photoluminescence yield from DNA-SWCNT in $\mathrm{pH}$ buffers with or without $1 \mathrm{mM}$ cysteine or hydrogen peroxide. Vertical lines show the $\mathrm{p} K_{\mathrm{a}}$ constants of the ssDNA coating. 